\title{
GESTÃO DOS RECURSOS COSTEIROS: UMA ANÁLISE DA PARTICIPAÇÃO LOCAL NA ZONA COSTEIRA DA PRAIA DE BILENE, PROVÍNCIA DE GAZA - MOÇAMBIQUE
}

\author{
Aniceto Elcídio Alves Macie* \\ Universidade Universidade Save de Moçambique -Extensão Maxixe
}

\author{
Apolinário Joaquim Malauene ${ }^{* *}$ \\ Universidade Pedagógica de Maputo
}

Resumo: Este estudo analisa as principais formas da participação das comunidades locais da Praia de Bilene na gestão dos recursos costeiros. No trabalho são apresentados aspetos gerais da gestão dos recursos costeiros, os principais problemas socioambientais e o estado de conservação dos ecossistemas costeiros da Praia de Bilene. 0 aporte metodológico se debruça pela análise de fontes documentais, bibliográficas e de trabalho de campo relacionadas à área de estudo. Assim, concluiu-se que a maioria da população local amostrada (64\%) não participa na gestão dos recursos costeiros da Praia de Bilene devido à inexistência de estratégias de gestão costeira integrada que prevelegiam modelos de gestão participativa e inclusiva dos recursos naturais. Nesta zona costeira existe uma forte pressão na destruição dos recursos costeiros impulsionada pelas atividades de natureza antrópica embora haja fiscalização dos profissionais da Administração Marítima. Os resultados sugerem que as zonas costeiras necessitam de ações integradas, participativas e inclusivas para a gestão dos recursos costeiros locais a fim de minimizar os problemas sócioambientais existentes e maximizar os benefícios que os atrativos naturais trazem para as comunidades locais.

Palavras-chave: Gestão dos Recursos Costeiros, Problemas socioambientais, Participação Local, Zona costeira da Praia de Bilene.

\section{MANAGEMENT OF COASTAL RESOURCES: AN ANALYSIS OF LOCAL PARTICIPATION IN THE COASTAL ZONE OF BILENE BEACH, GAZA PROVINCE - MOZAMBIQUE}

Abstract: This study analyzes the main forms of participation of the local communities on Bilene Beach in the management of coastal resources. The present work presents general aspects of the management of the coastal resources, the main socioenvironmental problems and the state of conservation in coastal ecosystems of the Beach of Bilene. The methodological contribution is based on the analysis of documentary, bibliographic and fieldwork sources related to the study area. Thus, it was concluded that the majority of the sampled local population (64\%) does not participate in the management of the coastal resources of the Bilene Beach due to the inexistence of integrated coastal management strategies that provide models of participatory and inclusive management of natural resources. In this coastal zone there is a strong pressure on the destruction of the coastal resources driven by activities of anthropic nature, although there is inspection of the professionals of the Maritime Administration. The results suggest that coastal zones need integrated, participatory and inclusive actions for the management of local coastal resources in order to minimize existing socio-environmental problems and maximize the benefits that natural attractions bring to local communities. Keywords: Management of Coastal Resources, Socio-environmental problems, Local participation, Coastal zone of Bilene beach.

\section{MANAGEMENT OF COASTAL RESOURCES: AN ANALYSIS OF LOCAL PARTICIPATION IN THE COASTAL ZONE OF BILENE BEACH, GAZA PROVINCE - MOZAMBIQUE}

Résumé: Cette étude analyse les principales formes de participation des communautés locales de Praia de Bilene à la gestion des ressources côtières. Le travail présente les aspects généraux de la gestion des ressources côtières, les principaux problèmes socio-environnementaux et l'état de conservation des écosystèmes côtiers de Praia de Bilene. La contribution méthodologique se concentre sur l'analyse à partir de sources documentaires, bibliographiques et sur le terrain liées à la zone d'étude. Ainsi, il a été conclu que la majorité de la population locale échantillonnée (64\%) ne participe pas à la gestion des les ressources côtières de la plage de Bilene en raison du manque de stratégies de gestion côtière intégrées qui prévalent des modèles de gestion participative et inclusive des ressources naturelles. Dans ce zone côtière il y a une forte pression sur la destruction des ressources côtières entraînée par des activités de nature anthropique bien qu'il y ait une inspection par des professionnels de l'administration Maritime. Les résultats suggèrent que les zones côtières ont besoin d'actions intégrées, participatives et inclusives pour la gestion des ressources côtières locales afin de minimiser les problèmes socio-environnementaux existants et maximiser les avantages que les attractions naturelles apportent aux communautés locales. Mots-clés: Gestion des ressources côtières, Problèmes socio-environnementaux, Participation locale, Zone côtière de Bilene Beach.

* Mestre em Geociências. Professor da Faculdade de Ciências da Terra e Ambiente, Universidade Save de Moçambique (UNISAVE - Extensão Maxixe). ORCID: 0000-0002-3616-9962 Email: anicetomacie@gmail.com

** Mestre em Geografia. Professor na Faculdade de Ciências da Terra e Ambiente, Universidade Pedagógica de Maputo, Departamento de Geografia; Universidade Pedagógica - Sede. Campus de Lhanguene, Av. de Moçambique, km 1 Maputo, Moçambique, Cidade de Maputo. Moçambique. ORCID: 0000-0002-4315-550X. Email: malawene1974@yahoo.com.br 
Introdução

Moçambique, nos últimos anos têm enfrentado problemas de natureza socioambiental inerente à gestão das zonas costeiras, a exemplo de países como Brasil, Portugal, Cabo Verde, entre outros. A natureza geográfica, cultural, socioeconómica, institucional e ambiental constituem elementos geoambientais que estabelecem os diferentes problemas socioambientais existentes. Os ecossistemas costeiros geralmente configuram-se frágeis e vulneráveis, dada baixa capacidade de regeneração quando destruídos e pelo aumento da pressão antrópica sobre os recursos existentes.

0 território Moçambicano apresenta cerca de 2.700 $\mathrm{km}$ de linha da costa, caracterizado por elevada diversidade de habitats extremamente sensíveis como as dunas, recifes de corais, praias arenosas, praias rochosas, ervas marinhas, mangais, baías, sistemas estuarinos e pantanosos. "Devido ao seu potencial e valor económico, a maior parte da costa é habitada por $40 \%$ da população, nela se desenvolvem as principais atividades económicas e de subsistência" (Hoguane et al., 2007). Estudos realizados nas zonas costeiras de Moçambique apontam em termos gerais que a destruição dos recursos costeiros é impulsionada principalmente por factores de origem antrópica, com destaque na crescente urbanização, no aumento da atividade turística com baixa fiscalização e na crescente dependência das comunidades locais com os recursos costeiros (Balidy et al., 2008; CDSZC, 2011; Hoguane et al., 2007; MICOA, 1998).

A Praia de Bilene é uma das regiões costeiras de Moçambique que apresenta uma diversidade constituída por praias com águas cristalinas, lagunas, abundância de espécies marinhas raras e de maior valor ecológico e económico, que no seu todo, servem de atrativos para o desenvolvimento turístico e local. Esta região abriga uma diversidade de ecossistemas de alta relevância ambiental e socioeconómica, marcada pela transição de ambientes terrestres e marinhos com interações que lhe confere um carácter de fragilidade devido à difícil capacidade de recuperação diante da grande concentração das actividades humanas. Portanto, a exploração destes recursos em forma de turismo, de pesca, da agricultura, necessita de uma gestão participativa de modo que se garanta a sua sustentabilidade. Desta forma é necessária uma atenção especial do poder público, privado e envolvimento massivo das comunidades locais, tidos como principais utilizadores e consumidores das potencialidades para a preservação desses recursos.

0 envolvimento da comunidade local na gestão de recursos costeiros em forma de modelo de gestão participativa é uma das ações sustentáveis que se sugere para o fomento do espírito conservacionista e preservacionista dos recursos costeiros. Esta pesquisa elenca os problemas socioambientais, estado de conservação dos ecossistemas, medidas para minimizar a degradação dos recursos costeiros, para além de compreender as formas de participação local na gestão dos recursos costeiros.

A zona costeira da Praia de Bilene, pelas suas características físico-geográficas enquadra-se na macro-unidade três das Dunas Parabólicas com cerca de 850 km de extensão, desde a ilha do Bazaruto até a fronteira meridional do País, indo até ao rio Mlalazi na África do Sul (MICOA, 1998). "Predomina nesta região o clima tropical húmido, com temperatura média anual que oscila entre $22^{\circ}$ e $24^{\circ} \mathrm{C}$. A precipitação média anual é de $1.200 \mathrm{~mm}$, na estação chuvosa, entre Outubro a Fevereiro "(Balidy et al., 2007).

Do ponto de vista geológico, a região apresenta Formações Quaternárias de dunas interiores e costeiras intercaladas por um cordão de lagoas costeiras (Balidy et al., 2008). As dunas interiores são caracterizadas por areias vermelhas pouco consolidadas e encontram-se a $4 \mathrm{~km}$ da Praia de Bilene e fazem parte da enorme planície arenosa constituída por areias eólicas do Pleistoceno Superior, com altitudes médias de $52 \mathrm{~m}$, as dunas mais recentes são compostas de areias brancas que avançam para o interior. As dunas costeiras do tipo parabólicas, constituída por planícies com uma altitude menor que $100 \mathrm{~m}$ estão dispostas em duas séries, sendo as mais próximas do mar mais baixas (menores que $80 \mathrm{~m}$ ) e as interiores mais altas (superiores a $80 \mathrm{~m}$ ).

Geomorfologicamente, esta região é caracterizada por ambientes sedimentares do Quaternário abarcando a praia de barreira, depósitos de delta de maré enchente, deltas de maré vazante, canal de marés, barreira de dunas eólicas, lagoas, praia de marés (nas margens Noroeste da lagoa) e pântanos (Balidy et al., 2008).

A pedologia é marcadamente arenosa de dunas costeiras caracterizadas por solos pouco evoluídos, de baixo nível de fertilidade e de retenção de água (MAE, 1986). As maiores partes desses solos litorais do sul de Moçambique pertencem à região pedológica dos solos zonais que se desenvolvem a partir de sedimentos não consolidados (Muchangos, 1999).

Os recursos hídricos da região são constituídos por rios (Chiguidine, Chicunda), lagoas (Massanguana, Nhacheúndezo, Bacheco, Ranzane, Uembezana, Chibana - Chirindeje, Zive, Xipete, Inhafubejama, Azul ou lagoa 
Bilene - São Martinho ou Uembje tida como a principal), que se orientam no sentido Oeste a Este (Balidy et al., 2007).

Segundo Muchangos (1999) o litoral da zona sul de Moçambique, em termos fito-geográficos, caracteriza-se por uma vegetação mista, arbórea, arbustiva com estratos herbáceos de floresta dunar. Enquadra-se no Mosaico Regional de Tongoland Pondoland constituído por ecossistemas terrestres e aquáticos. A zona costeira da Praia de Bilene apresenta quatro (4) tipos diferentes de vegetação, nomeadamente: i) Vegetação das dunas costeiras na margem sul das lagoas, composta por espécies pioneiras herbáceas fixadoras de areia, que variam de brenhas ou florestas costeiras em direção ao interior; ii) Floresta de casuarinas que por sinal é a mais destruída, caracterizada pela existência de aves diversas, mamíferos, répteis e insectos. As espécies marinhas são constituídas por diversificados peixes, crustáceos, olutúrias e tartarugas marinhas; iii) Brenha costeira que ocorre no topo das dunas, que separam as lagoas do mar aberto e apresentam um estrato arbóreo a herbáceo. A fauna é constituída por mamíferos de pequeno porte e espécies de pássaros; iv) Floresta ribeirinha ocorre em volta da lagoa do bilene e ao longo do rio que liga essa lagoa. As espécies são herbáceas e arbóreas, e a fauna é caracterizada por aves, répteis e mamíferos; e a vegetação graminal arbórea das planícies e dunas interiores ocorre nas encostas dos vales dos rios e nas dunas interiores.

Esta região apresenta quatro (4) ecossistemas aquáticos: i) Mar aberto caracterizado por um substrato rochoso onde a rebentação das ondas ocorre junto das rochas. Nesta área ocorrem espécies como tartarugas marinhas, ervas marinha e macro algas; ii) Praia arenosa é zona onde nidificam as tartarugas marinhas, podendo-se verificar a tartaruga cabeçuda ou comum, a tartaruga coriácea e a tartaruga verde (Figura 1), predomina também algumas espécies de caranguejos, crustáceos, gado bovino e algumas espécies de peixes.

Figura 1: Zona de Nidificação de Tartarugas Marinhas - Praia Arenosa

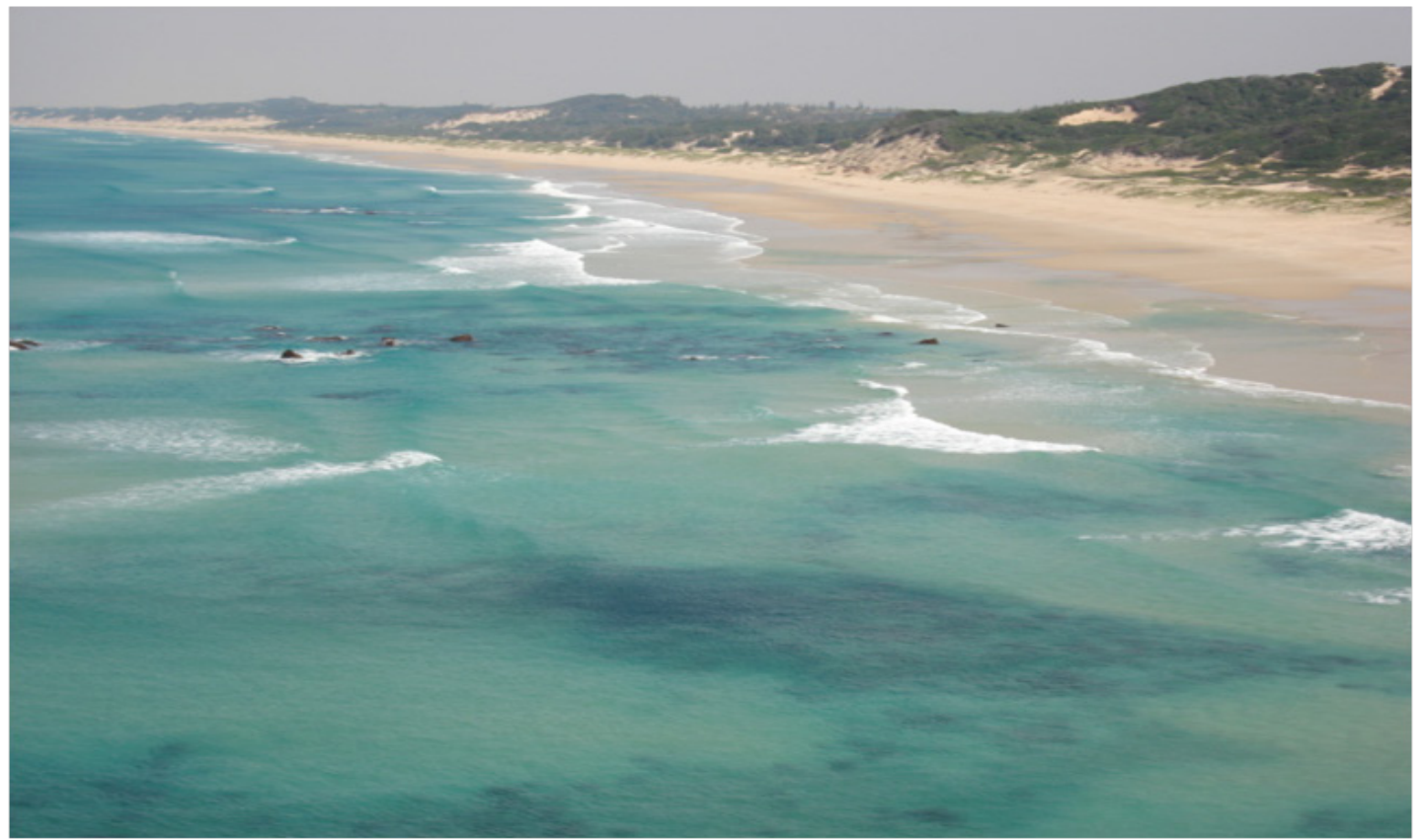

Fonte: AMPB, 2011.

iii) Águas salobras da lagoa do Bilene situam-se numa área baixa, que periodicamente tem ligação com o mar aberto. A vegetação apresenta estratos herbáceos como ervas marinha cuja única espécie identificada é a Ruppia maritima que no nível do país apenas ocorre neste local. A fauna é constituída por aves, peixes, anfíbios e répteis diversificados (Balidy et al., 2008). iv) Sistema de riachos, lagoas de água doce e pântanos, são constituídos por todas as lagoas que desaguam na lagoa de Bilene. A vegetação da lagoa azul é composta por plantas flutuantes e a fauna é constituída por aves e espécies de peixe. Os Pântanos localizam-se em vales das dunas, numa vegetação densa no ocidente da Lagoa do Bilene. 


\section{Modelo de Gestão Costeira Integrada}

A Gestão dos Recursos Costeiros (GRC) é um modelo que procura dar respostas aos benefícios que as comunidades ganham das actividades exercidas nas áreas ecologicamente e previamente estabelecidas. Há que referir que existem muitos modelos de gestão dos recursos embora este trabalho vá se centrar apenas no "Modelo Gestão Integrada dos Recursos Costeiros (GIRC)" que é tido como o mais actual na história da gestão dos recursos costeiros por ultrapassar a visão tradicional setorialista e fazer abordagem integrada e holística. Portanto, objetiva melhorar a qualidade de vida das comunidades locais de que dependem dos recursos costeiros e leva em consideração a manutenção da diversidade biológica e a produtividade dos ecossistemas costeiros. Assim, a GIRC é concebida como um processo contínuo, participativo e evolucionário que visa salvaguardar os interesses das comunidades presentes e garantir os recursos para as futuras gerações. De acordo com Sain (1993) apud Belchior (2008) "as decisões na GIRC são tomadas de forma contínua e dinâmica para o uso sustentável, desenvolvimento e proteção dos recursos nas áreas costeiras e marinhas". Entretanto, a GIRC deve-se obedecer cinco (5) etapas, conhecidas como ciclo de Gestão Costeira Integrada (Pollete, 2011): diagnóstico, planificação, adopção formal e avaliação (figura 2).

Figura 2: Ciclo de Gestão Costeira Integrada

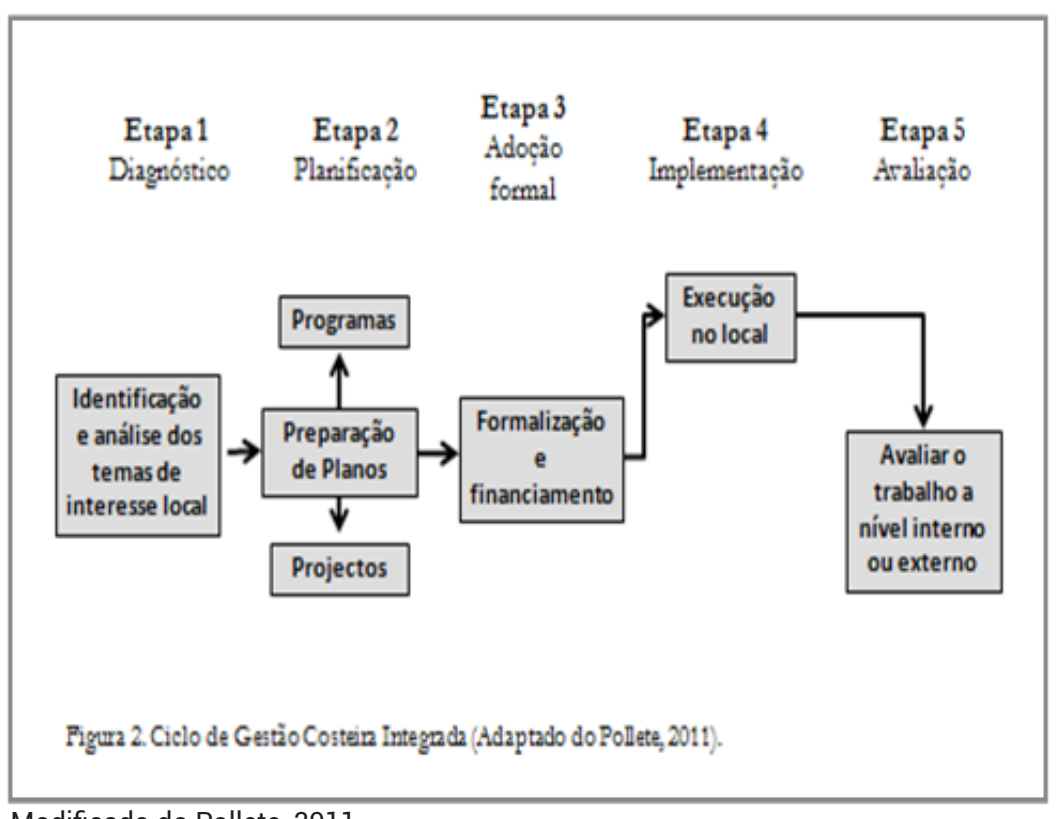

Modificado do Pollete, 2011.

Por conseguinte, é necessário numa primeira fase, procurar identificar os principais problemas socioambientais do local, analisar e apurar prioridades. De seguida faz-se um plano em forma de projeto ou programa objetivando a sua efetivação. Depois se procedem à formalização do mesmo em órgãos governamentais de modo a verificar as suas viabilidades, recursos materiais e financeiros. Após aprovação do projeto, é implementado no local escolhido, e por fim faz-se uma avaliação, na qual envolve assuntos intrínsecos e extrínsecos. Diante das situações indesejadas (algumas falhas) na implementação, o projeto é reavaliado e torna-se o modelo contínuo e participativo (Pollete, 2011).
Em Moçambique, a prática da GIZC rege-se a três (3) princípios nomeadamente: participação, coordenação e integração (MICOA, 2005). Na participação, a comunidade local e outros interessados, são os utilizadores e os primeiros beneficiários da zona costeira. Na coordenação, diferentes instituições com papel de gestão ou fiscalização das zonas costeiras funcionam de uma forma setorial visando salvaguardar os recursos e os interesses locais. Por fim, na integração se potencializa o desenvolvimento sustentável para que seja eficaz, desenvolvendo a região, respeitando diversos fatores que caracterizam a natureza da zona costeira. Contudo, atualmente, com os princípios do uso racional dos recursos naturais, há tendência do 
envolvimento da comunidade local em ações que visam promover a sustentabilidade com um enfoque participativo integrando todos os atores locais no processo de elaboração e tomada de decisões.

\section{Material e Métodos}

\section{Área de estudo}

A zona costeira da Praia de Bilene têm cerca de 25 km de extensão da costa em relação ao Oceano Índico e uma superfície de $2.719 \mathrm{Km} 2$. Localizada na região Sul da província de Gaza, distrito de Bilene - Macia, situa-se entre os paralelos $25^{\circ} 12^{\prime} 00^{\prime \prime}$ e $25^{\circ} 25^{\prime} 40^{\prime \prime}$ de latitude Sul, e entre os meridianos $33^{\circ} 07^{\prime} 51^{\prime \prime}$ e $33^{\circ} 21^{\prime} 15^{\prime \prime}$ de longitude Este (Figura 3). Limita-se ao Norte pelo Posto Administrativo de Macuane, ao Sul pelo Oceano Índico, a
Leste com o distrito de Xai-Xai através do Posto Administrativo de Zongoene, e a Oeste com o distrito da Manhiça (CDSZC, 2011). É constituído por cinco (5) bairros, nomeadamente: Tsoveca, Mahungo, Chilengue, Mhata, Nhiuane.

\section{Procedimento para a coleta e ánalise de dados}

Para a realização desta pesquisa recorreu-se inicialmente a revisão bibliográfica que consistiu na leitura de obras já elaboradas de modo a buscar informações necessárias para a fundamentação do tema em estudo. Em seguida, fez-se a coleta de dados no campo. Para tal, primeiro definiu-se o tipo de amostragem e em seguida o tamanho da amostra, tendo como critérios de escolha

Figura 3: Localização geográfica da área de estudo

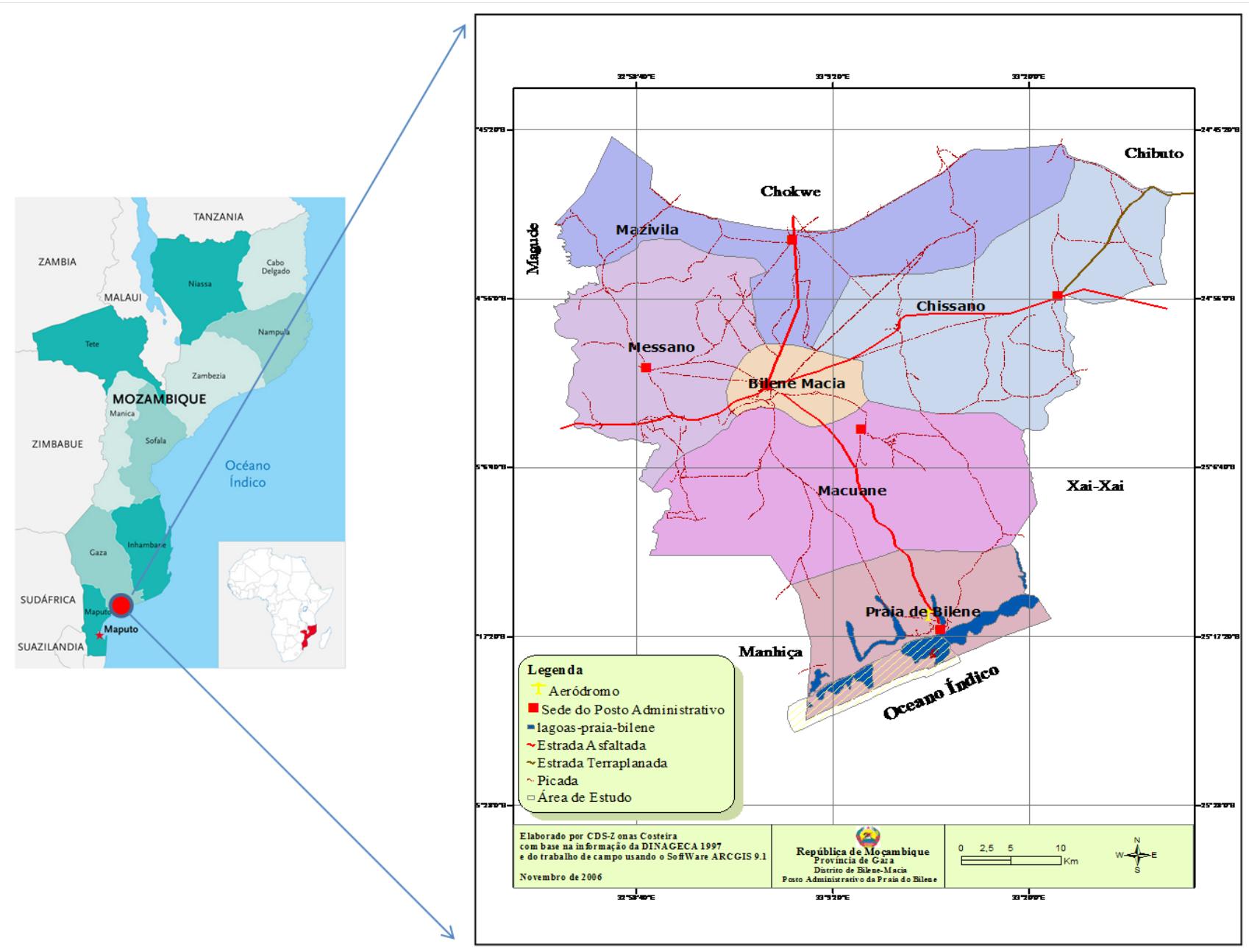

Fonte: Modificado do CDSZC, 2011. 
da amostra: ser chefe da família, ser maior de 18 anos e residir a mais de cinco anos na Praia de Bilene. Portanto, optou-se na amostragem estratificada proporcional que consiste em dividir a população em estratos para depois selecionar uma amostra aleatória em cada um dos estratos (Mulenga, 2004). Conforme o mesmo autor, este tipo de amostragem é prático e vantajoso usar sempre que a amostra a selecionar não for grande $n<10$. 000. A área de estudo segundo possui uma população de 7.992 habitantes (INE, 2007). No entanto, os bairros foram considerados estratos, sendo que a região possui cinco (5) bairros que são estratos homogéneos e, em cada bairro foram aleatoriamente selecionados quinze (15) chefes de agregados familiares, que no seu todo, perfizeram setenta e cinco (75) chefes de agregados familiares correspondentes à amostra estudada. Foram realizadas entrevistas padronizadas ou estruturadas que consistiram em fazer uma série de perguntas aos informantes segundo um roteiro de perguntas preestabelecidas. As entrevistas foram aplicadas ao chefe do Posto Administrativo da Praia de Bilene, Técnico da Administração Marítima da Praia de Bilene, e Técnico do Centro de Desenvolvimento Sustentável da Zona Costeira de Xai-Xai. 0 questionário com um roteiro de perguntas abertas e fechadas foi aplicado à comunidade local da região da Praia de Bilene. Como forma de complementar assunto não previstos no questionário foram também feitas entrevistas desapadronizadas ou não estruturadas que consistiram numa conversação informal alimentada por perguntas abertas preestabelecidas no questionário com vista a proporcionar maior liberdade ao informante.

Para análise de dados obtidos se usou o método Estatístico que na asserção de Gil (2003), "constitui importante auxílio para investigação em ciências sociais ou aplicadas". Com base neste método, foi feito o cálculo de proporções de acordo com frequências das respostas fornecidas nos questionários e tabulação dos dados coletados.

\section{Resultados e Discussão}

Nesta pesquisa se constatou um défice da participação local na gestão dos recursos costeiros, daí que se propõe um paradigma centrado na Gestão Participativa das Zonas Costeiras. Este modelo de acordo com Belchior (2008) "visa assegurar o envolvimento de toda comunidade local ou grupos sociais através da potencialização de responsabilidades sociais, integração de valores sociais nas decisões gerenciais". Portanto, este modelo processa-se através da participação pública, troca de conselhos e informações, partilha de poder, onde o governo faz consultas à comunidade local e responsabilização de todos os setores e da comunidade local para execução dos programas.

De um modo geral, a gestão dos recursos costeiros é atualmente um tema relevante dado à fragilidade dos ecossistemas costeiros. Enquadra-se na preocupação mundial sobre "a sustentabilidade na terra" na qual os recursos naturais representam a parte crucial na medida em que são o garante da sobrevivência das presentes e continuidade das futuras gerações. 0 tema constitui também um dos objetivos da Agenda 21 de Moçambique, capítulo17 que versa sobre "a proteção dos oceanos, mares fechados e semifechados, zonas costeiras".

Estado de conservação dos ecossistemas costeiros

Os ecossistemas aquáticos e terrestres da Praia de Bilene apresentam níveis consideráveis de degradação (Tabela 1) devido a fatores de origem antrópica (AMPB, 2011; CDSZC, 2011). A pressão das comunidades locais constitui a grande ameaça para estes ecossistemas devido às atividades praticadas nesta região costeira.

Os fatores mais comuns que contribuem para a degradação dos recursos costeiros da Praia de Bilene são: a destruição da vegetação para fins de urbanização, construção de habitações de veraneio e infraestruturas turísticas (Figura 4) sem respeitar as margens das lagoas marinhas, e para abertura de novos campos agrícolas; queimadas descontroladas originadas pelos pescadores assim como pelos camponeses durante a abertura dos campos agrícolas e pelos criadores de gabo bovino durante a renovação do capim para fins de pastagem. A fauna costeira envolvente é destruída pela pesca desenfreada que usa técnicas e instrumentos precários (redes mosquiteiras) e não adequados para pesca e que acabam por retirar espécies em fase de crescimento. A proliferação do lixo é também realizada durante a prática turística. Os nacionais (comunidade local) têm pautado por fecalismo a céu aberto por insuficiência de sanitários públicos e os estrangeiros têm destruído os ninhos das tartarugas marinhas na praia arenosa com a condução de veículos motorizados não autorizados na faixa dos $100 \mathrm{~m}$ (proibidos pela lei). Estes resultados foram também encontrados no estudo feito por Balidy et al., (2008), onde foi constatado que a zona costeira da praia de Bilene apresenta problemas ambientais resultado de atividades de origem antropogênicas. 
Tabela 1: Estado de conservação dos ecossistemas costeiros da Praia de Bilene

\begin{tabular}{|c|c|c|}
\hline Ecossistemas aquáticos e terrestres da Praia de Bilene & Estado de conservação & Fatores condicionantes \\
\hline $\begin{array}{c}\text { Floresta ribeirinha e graminal arbóreo das planicies e dunas } \\
\text { interiores }\end{array}$ & $\begin{array}{l}\text { Relativamente conservada, com tendências de destruição da vegetaçãa. } \\
\text { Abertura de campos agricolas pelos locais }\end{array}$ & Abertura de campos agrícolas pelos locais \\
\hline Floresta ou brenha costeira & Alto nivel de desmatamento principalmente nas margens da lagoa de Bilene & $\begin{array}{l}\text { Concessões de terra para implantação de estâncias turísticas que continuam a um ritmo acelerado, po- } \\
\text { dendo-se verificar dunas e vegetaçãao dunar destruída para dar espaço a estes empreendimentos. }\end{array}$ \\
\hline Floresta de casuarinas & Encontra-se num estado crítico de degradação & $\begin{array}{c}\text { Maior pressão e destruição pela comunidade local devido ao abate indiscriminado da vegetação a busca } \\
\text { de material de construção, combustivel lenhoso e matéria-prima para o fabrico do carvão vegetal; } \\
\text { Pressão das queimadas descontroladas;; } \\
\text { Abertura desordenada de estradas para acesso de viaturas a praia do mar aberto. }\end{array}$ \\
\hline Zona das margens da lagoa de Bilene & Alto nivel de degradação nas margens da Lagoa de Bilene & $\begin{array}{l}\text { Pressão de ocupação de terra, principalmente pelos turistas estrangeiros (área preferida); } \\
\text { Aumento da ocupaçâao humana por volta da Lagoa do Bilene e por consequência existe perda da biodi- } \\
\text { versidade circudante; }\end{array}$ \\
\hline Zona das encostas das dunas interiores & Indicios de degradação das dunas interiores & Práticas agrícolas não adequadas e a criação de gado bovino. \\
\hline Praia arenosa & Destruição dos ninhos das tartarugas marinha & Condução de véiculos motorizados na faixa dos $100 \mathrm{~m}$ (proibidos na lei) por turistas. \\
\hline
\end{tabular}

Figura 4: Construção de habitações de veraneio nas dunas primárias

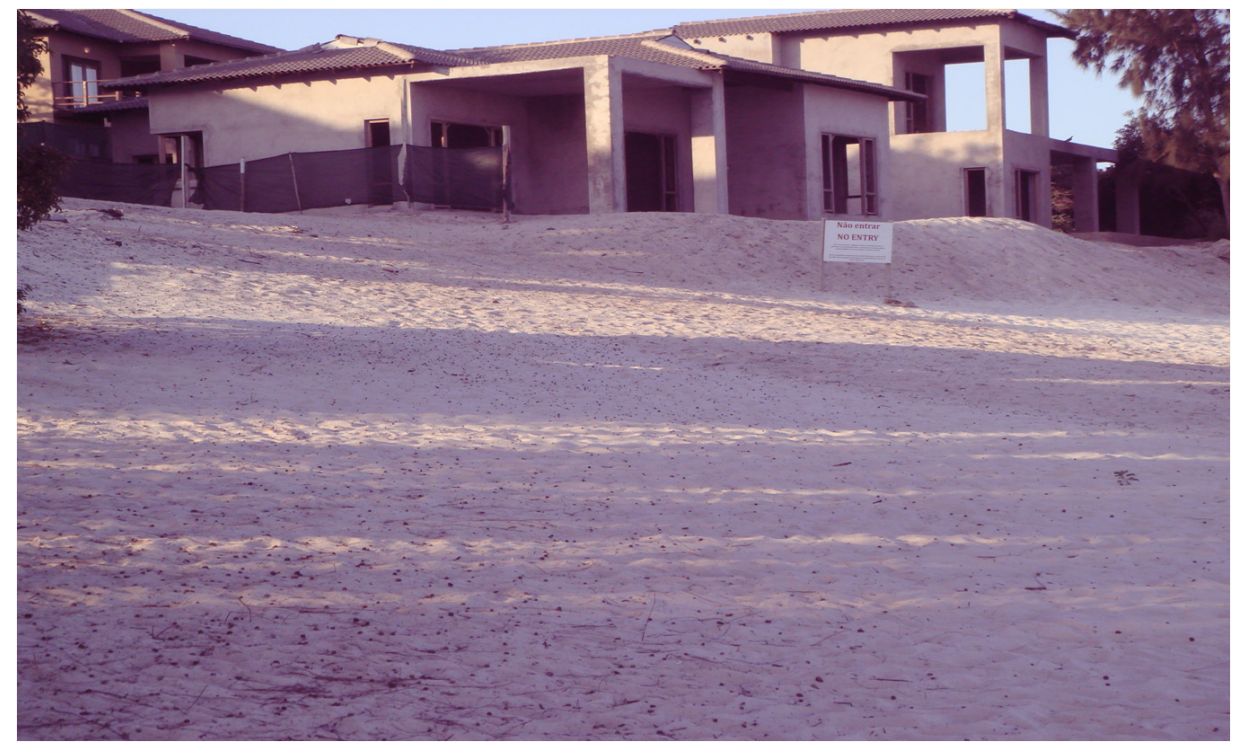

\section{Gestão dos Recursos Costeiros na Praia de Bilene}

A gestão dos recursos costeiros (GRC) surge em parte, da necessidade de resolver os problemas socioambientais que afectam os ecossistemas costeiros da Praia de Bilene tidos como frágeis dadas a sua baixa capacidade de regeneração quando destruídos e a sua localização em um ambiente de transição. Esta região costeira é um dos principais destinos turísticos da região sul de Moçambique, apresenta áreas com baixo, médio e alto grau de degradação dos recursos costeiros cujos fatores condicionantes estão apresentados na Tabela 1. Os dados coletados revelam que a atividade turística, a crescente urbanização, a pesca desenfreada (uso técnicas e instrumentos precários) para além se serem factores condicionantes da perda da biodiversidade na costa, são atividades com baixa fiscalização. Como consequência à crescente procura e dependência dos recursos costeiros por parte das comunidades locais com objetivos de satisfazer as necessidades alimenta- 
res, comerciais e turísticas, contribuem para a perda da vegetação costeira, fauna costeira (tartarugas marinhas, espécie protegida) e o assoreamento da lagoa de Bilene (principal atrativo turístico). A população local quando questionada sobre a principal actividade económica, a maioria dedica-se a pesca artesanal (42\%), seguido do comércio (31\%) (Figura 5).
Entretanto, a pesca na lagoa do Bilene é a atividade mais praticada pela comunidade local, com recurso a rede com polegadas menores ou mosquiteiras que também tem capturado espécies menores ainda em fase de crescimento. Esta atividade depende principalmente da abertura do canal das dores (canal que liga a lagoa com o Oceano Índico). A pesca é realizada em três (3)

Figura 5: Diagrama das principais atividades Económicas

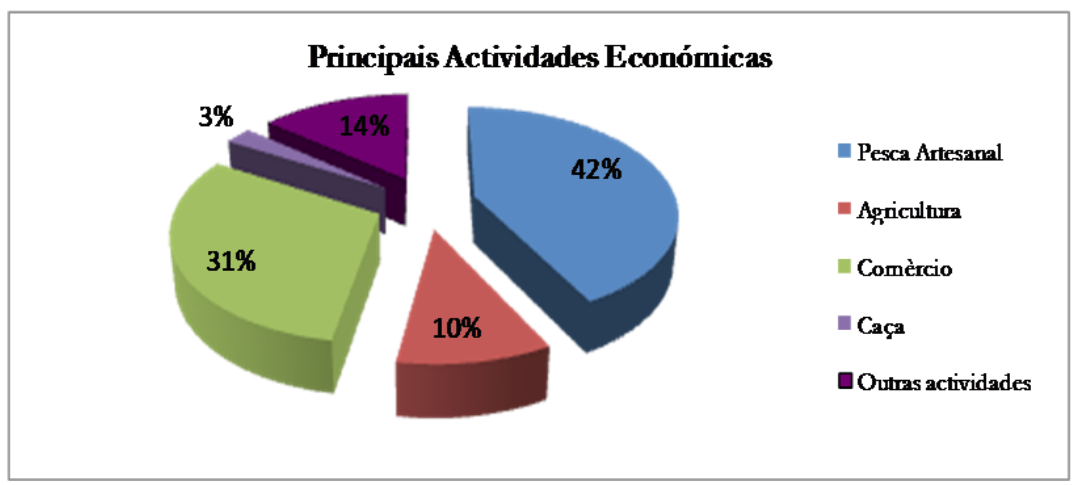

principais centros pesqueiros: Tsoveca, próximo ao restaurante do complexo turístico dos Caminhos de Ferro e no extremo ocidental da lagoa, em Nhangono. 0 desaparecimento de várias espécies marinhas observa-se no período em que o canal está fechado e o contrário (fluxo das espécies) quando o canal abre. Nesta atividade há incumprimento dos períodos de defeso na lagoa de Bilene, podendo-se verificar desmandos por parte de alguns pescadores, pelo facto de pescarem no período de defeso de forma clandestina. As espécies que sofrem maior exploração são: bicuda e Xereua (são as mais exploradas e comercializadas), garropa, holtúrios e raias. As tartarugas marinhas em vias de extinção são abatidas para a venda aos turistas estrangeiros (de origem Asiática principalmente) assim como para o fabrico de objetos de ornamentação.

0 comércio, com destaque de produtos de artesanato faz com que haja também a destruição da flora costeira na medida em que a comunidade destrói a vegetação para a obtenção da matéria-prima para o fabrico desses objetos. Assim, de um modo geral estas atividades quando não fiscalizadas, contribuem para a perda da biodiversidade costeira em Bilene, visto que não são praticadas de forma sustentável embora haja alguma tendência de uso racional devido algumas campanhas de sensibilização dirigidas pelos técnicos do Centro de Desenvolvimento Sustentável das Zonas Costeiras de Xai-Xai e da Administração Marítima da Praia de Bilene.

\section{Problemas Socioambientais da Praia de Bilene}

A zona costeira da Praia de Bilene, segundo os dados de trabalho de campo apresenta problemas socioambientais de diversa natureza apresentados na Tabela 2 que se segue:

Entretanto, de acordo com o estudo realizado por MICOA (1998) "a maioria dos problemas socioambientais apresentados na Tabela 2, é típica das zonas costeiras de Moçambique, protagonizados principalmente por turistas nacionais e pelas comunidades locais que ainda não possuem uma sólida educação ambiental". Assim, de acordo com este órgão governamental, como forma de salvaguardar os ecossistemas costeiros e difundir ações de uso racional dos recursos costeiros, tem-se realizado projetos e propagandas contínuas e sistemáticas de preservação ambiental nas comunidades locais costeiras com objetivo de incutir a atitude de uso racional desses recursos. 
Tabela 2: Problemas socioambientais da Praia de Bilene

\begin{tabular}{|c|c|}
\hline Natureza & Problemas Sócioambientais \\
\hline Turística & $\begin{array}{l}\text { - Assoreamento da lagoa do Bilene tido como principal atrativo turístico devido a destruição da vegetação } \\
\text { circundante e das dunas para a construção empreendimentos turísticos, deixando os solos susceptíveis a } \\
\text { erosão; } \\
\text { - O não cumprimento de critérios legislativos na construção e localização das instâncias turísticas e servi- } \\
\text { ços complementares, visto que foram construídos em cima das formações dunares; } \\
\text { - Aumento cada vez mais de pescadores artesanais na Lagoa do Bilene e exercício da actividade pesqueira } \\
\text { sem licenciamento (pesca ilegal); } \\
\text { - Baixo nível de saneamento e drenagem (recolha e tratamento de lixo, fecalismo a céu aberto, falta de } \\
\text { sanitários públicos; } \\
\text { - A poluição da lagoa a partir da proliferação dos resíduos sólidos originada pelos banhistas principalmen- } \\
\text { te. }\end{array}$ \\
\hline Ambiental & $\begin{array}{l}\text { - Derrube da floresta dunar para a construção, extracção da lenha para produção do combustível lenhoso e } \\
\text { para produção de carvão e consequentemente desaparecimento da avifauna que habita na flora; } \\
\text { - Prática de queimadas descontroladas protagonizadas pelos pescadores, camponeses e criadores de } \\
\text { gado, principalmente; } \\
\text { - A captura de espécies protegidas como as tartarugas marinhas para o fabrico de objectos de ornamenta- } \\
\text { ção assim como para a comercialização; Circulação de viaturas e motos na faixa dos } 100 \text { metros da costa } \\
\text { tida como ameaça aos habitats e especialmente na zona de nidificação das tartarugas marinhas; } \\
\text { - Erosão nas dunas costeiras, resultado da destruição da vegetação para construção de habitações e } \\
\text { estâncias turísticas. }\end{array}$ \\
\hline
\end{tabular}

\section{A Participação local na Gestão dos Recursos Costeiros}

Os recursos naturais catalisam o desenvolvimento das sociedades modernas e a população tem responsabilidade de conserva-la embora seja o principal agente de degradação (Araújo, 1997). Dai que é importante envolver a população na gestão dos recursos naturais com base em paradigma de gestão participativa dos recursos costeiros (Belchior, 2008), proposto para a minimização dos problemas socioambientais que afetam a região da Praia de Bilene.

"A participação comunitária é um conjunto de esforços organizados pelos atores sociais para incrementar o controlo dos recursos numa dada situação sociais (Francis, 1996)". Conforme Drake apud Araújo (1997), "a participação da comunidade local é uma habilidade criativa, em forma de projetos de desenvolvimento que tenham algum impacto sobre interesses sociais locais". Tendo em conta a asserção dos autores supracitados, a participação pressupõe envolvimento de diversas entidades, formulação de políticas e tomada de decisões no processo de desenvolvimento de atividades do seu interesse local. E, por conseguinte a participação comunitária importa a tomada de decisões sob-responsabilidades das autoridades nas áreas onde se verificam os recursos sem, no entanto alterar o estado natural dos ecossistemas, através da elaboração de projectos sus- tentáveis de desenvolvimento, conservação e preservação de recursos costeiros que por sua vez terão impacto positivo nas comunidades.

Segundo os dados da AMPB (2011), a Praia de Bilene dispõe de um manancial diversificado de recursos costeiros florísticos (floresta de casuarinas, ervas marinhas, corais, etc. e faunísticos (tartarugas marinhas, aves, répteis, diversos tipos de peixes) dos quais são destruídos como forma de satisfação das necessidades básicas dos locais assim como para comercialização aos turistas de origem estrangeira principalmente. As famílias de baixa renda são as que exploram os recursos maioritariamente, podendo se destacar na flora costeira a exploração excessiva de espécies de casuarinas (para servir de material de construção, obtenção lenha e para produção do carvão), as ervas marinhas e os corais (para o fabrico de objetos de ornamentação e comercialização aos turistas estrangeiros principalmente). Conforme os dados do questionário, 93\% dos chefes de agregados inqueridos afirmam que existe uma pressão sobre os recursos costeiros, com destaque a fauna costeira (exploração de espécies como tartarugas marinhas, peixes - bicuda, xereua, pedra, garroupa) destinada ao consumo e comercialização, e espécies de holtúrios que sofrem a predação humana com objectivo de serem comercializados principalmente para indivíduos de origem chinesa.

No que refere à participação das comunidades locais, a maioria (64\%) afirmou que não participa na gestão dos 
Figura 6: Diagrama da participação local na Gestão de Recursos Costeiros

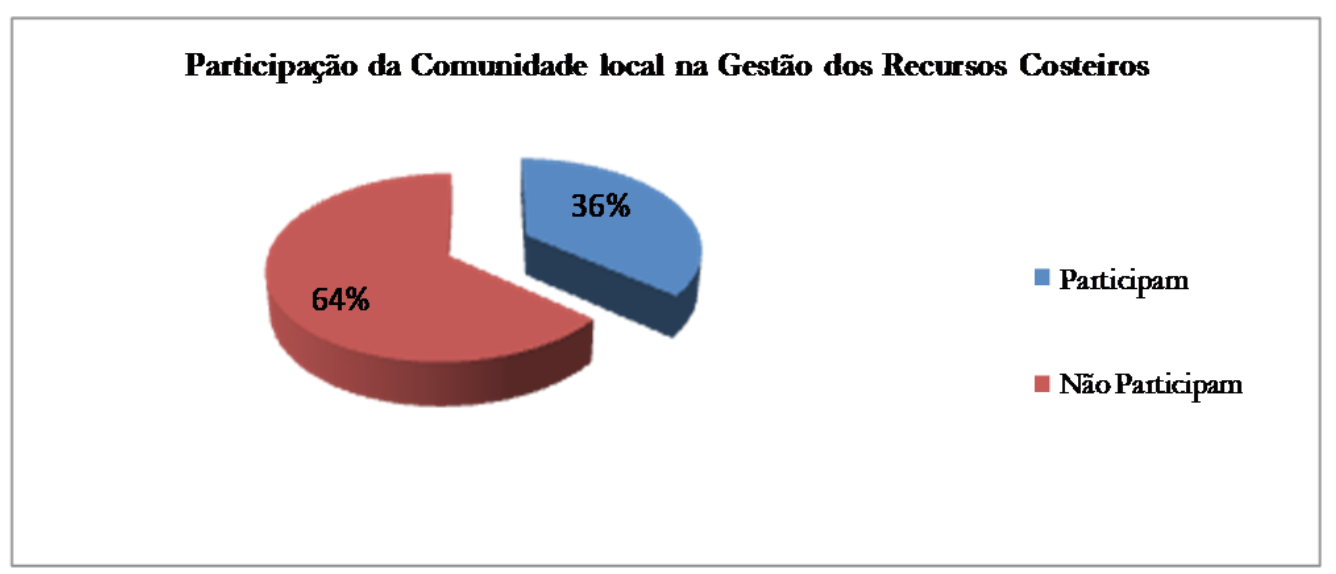

recursos costeiros, se revelando em uma fraca participação (Figura 6).

Questionados sobre os fatores que contribuem para a fraca participação constatou-se que a falta de associações e clubes de ambiente comunitários para abertura de debates, campanhas de sensibilização de diferentes faixas etárias no tocante a importância do uso sustentável dos recursos costerisos, a insuficiência de fiscais comunitários de preferência nativos, o aumento da população aliado ao desemprego e a insegurança alimentar contribui para o baixo envolvimento da população local na GRC.

A participação da comunidade local existente (36\%) embora não seja satisfatória, configura-se da seguinte forma: criação de associações comunitárias, clubes de ambiente e formação de fiscais comunitários; participação nas campanhas de sensibilização e consciencialização ambiental; cumprimento dos períodos de defeso que variam de 2 a 4 meses cuja pesca é estritamente proibida; participação nas jornadas de limpeza nas margens da lagoa e na Praia de Bilene; participação em programas de revegetação nas áreas críticas como é o caso da floresta de casuarinas; participação em reuniões e conselhos comunitários, e levantamento de denúncias por locais às entidades competentes (Serviçõs Provinciais de Floresta e Fauna Bravia, Administração Marítima da Praia de Bilene e Centro de Desenvolvimento Sustentável das Zonas Costeiras de Xai-xai) sobre indivíduos que transgridem as leis que regem sobre a conservação dos recursos costeiros e marinhos; e a fiscalização comunitária de embarcações no alto mar (principalmente dos turistas estrangeiros), com vista a salvaguardar as espécies protegidas (tartarugas marinhas) referenciadas no Regulamento de Pesca Recreativa e Desportiva de 2003.

\section{Ações para melhoria da Gestão dos Recursos Cos- teiros na Praia de Bilene}

Como forma de salvaguardar e minimizar a destruição dos recursos costeiros da Praia de Bilene, tendo em conta os problemas socioambientais constatados nesta pesquisa, sugere-se o descrito na tabela 3 .

Contudo, as sugestões agrupadas na tabela 3 vão ajudar traçado de estratégias de gestão participativa, que incluam as comunidades locais em todos os processos de tomada de decisão, além da apresentação de diferentes mecanismos cuja implementação pode minimizar os problemas socioambientais existentes na região costeira da Praia de Bilene.

\section{Conclusão}

Face aos problemas constatados sobre a Gestão Integrada dos Recursos Costeiros, aliado a fraca participação da comunidade local na gestão destes recursos, se pressupõe que a gestão participativa e inclusiva dos recursos costeiros poderia minimizar os problemas socioeconómicos existentes. Isto porque estes modelos de gestão têm carácter participativo, contínuo e interactivo, onde o sucesso depende da aderência e participação dos locais de direito sobre os recursos, visto que eles constituem os principais agentes da destruição da fauna e flora costeira.

A participação da comunidade local na gestão dos recursos costeiros na Praia de Bilene embora exista, não é satisfatória em termos práticos, pois $64 \%$ da comunidade local não participam nessa gestão. Sendo assim, a fraca participação local contribui de certa forma para o insucesso de alguns programas ou projetos de Ges- 
Tabela 3: Ações para melhoria na Gestão dos Recursos Costeiros

\begin{tabular}{|c|c|}
\hline Níveis setoriais & Ações \\
\hline Governo & $\begin{array}{l}\text { - Integrar as comunidades locais em programas e projetos de gestão costeira integrada com vista a melho- } \\
\text { rar os níveis: socioambientais e económicos; } \\
\text { - Criar sistemas participativos de gestão de pescarias baseada na cogestão; } \\
\text { - Envolver membros da comunidade local nos conselhos de gestão costeira de modo a darem a sua contri- } \\
\text { buição face aos problemas vigentes; } \\
\text { - Criar mecanismos de incentivos económicos para maior aderência em atividades de revegetação, jor- } \\
\text { nadas de limpeza da costa e contribuição nos aspetos práticos (atividades) e teóricos (ideias) sobre as } \\
\text { formas eficazes de conservar os recursos; } \\
\text { - Fazer um ordenamento em nível da região separando pelas atividades socioeconómicas de modo a incutir } \\
\text { as boas práticas de uso e aproveitamento da terra. }\end{array}$ \\
\hline Comunidade local & $\begin{array}{l}\text { - Criar associações e formação de fiscais comunitários destinados à proteção dos recursos costeiros; } \\
\text { - Investir na compra e utilização de instrumentos legais para o exercício da atividade pesqueira; } \\
\text { - Promover o uso de métodos e equipamentos seletivos de pesca, capazes de minimizar os desperdícios na } \\
\text { captura das espécies e minimizar a captura da fauna acompanhante; } \\
\text { - Desenhar projetos de conservação ex-situ de espécies marinhas como peixes com vista à multiplicação } \\
\text { destes e criação do auto emprego. }\end{array}$ \\
\hline Pessoal da educação & $\begin{array}{l}\text { - Sensibilização ou consciencializar à comunidade local em matérias de gestão e conservação dos recur- } \\
\text { sos costeiros através da educação ambiental formal, informal e não formal com vista a retirar o espírito } \\
\text { de destruição por ignorância ou pela ganância, e incutir atitudes conservacionista e preservancionista dos } \\
\text { recursos costeiros; } \\
\text { - Criar de clubes do ambiente nas escolas, que terão como linhas de ação: debate em matérias de gestão } \\
\text { ambiental, criação de florestas comunitárias, promoção e divulgação da importância de conservação e } \\
\text { preservação dos recursos naturais costeiros. }\end{array}$ \\
\hline
\end{tabular}

tão dos Recursos Costeiros. Esta região é afetada por problemas ambientais, como o assoreamento da lagoa de Bilene devido à destruição da vegetação circundante e exposição das dunas a erosão, destruição e aplanação do relevo dunar para a construção de habitações de veraneio e estâncias turísticas, destruição da vegetação que, além de servir de habitat de muitas espécies faunísticas, serve de purificador do ar.

Para melhoria dos problemas socioambientais existentes é importante que se olhe nas condições da população local, envolvimento dos locais em programas e projetos da região, e é fundamental a consciencialização ambiental contínua com vista a incutir na comunidade novos paradigmas de desenvolvimento socioeconómico baseados numa gestão integrada e participativa dos recursos costeiros.

Contudo, é decisiva a integração da iniciativa local e privada, formando esforços comuns com vista a encontrar soluções adequadas para o bem-estar social da população local.

\section{Agradecimentos}

O nosso especial agradecimento vai a Universidade Pedagógica - Sede, Faculdade de Ciências da Terra e Ambiente, Departamento de Geografia, pela pesquisa realizada no âmbito da culminação do curso de Licenciatura em Ensino de Geografia.

Em particular, agradece-se ao Mestre Apolinário Malauene, pelo apoio, dedicação e orientação para que a pesquisa se tornasse uma realidade.

Aos Técnicos: Pelágio Duvane (Técnico da Administração Marítima da Praia de Bilene), Jacinta e Jiade (Centro de Desenvolvimento Sustentável das Zonas Costeiras - Xai-Xai) e ao Casimiro Matabel (Chefe do Posto Administrativo da Praia de Bilene), pelas discussões e informações disponibilizadas no âmbito do trabalho de campo. 


\section{Referências}

AMPB - Administração Marítima da Praia de Bilene. (2011). Instituto de Navegação Marinha (INAMAR) de Moçambique. Distrito de Bilene - Macia.

ARAÚJJO, M. J. M.. (1997). Geografia dos Povoamentos: Assentamentos Humanos e Urbanos, Maputo, UEM, Editora Livraria Universitária.

BALIDY, et al.,. (2007). Área de Proteção Marinha e Costeira da Praia de Bilene: Situação Bio-Física e Socioeconómica Atual Projeto de Gestão Integrada da Zona Costeira, Fase II. Volume I, DPCA-Gaza e CDS-ZC/MICOA. Xai-Xai.

(2008). Reserva Especial do Bilene. Situação Biofísica e Socioeconómica Atual. In Projeto de Gestão Integrada Fase III, Componente Desenvolvimento Costeiro Volume I. CDS-Zonas Costeiras, MICOA, Xai-Xai.

BELCHIOR, Constância C.. (2008). Gestão Integrada: estudo de caso do Projeto Economage na região Estuarina de Santos São Vicente. Tese (Mestrado), São Paulo, Universidade de São Paulo, Instituto de Energias e Ambiente.

CDSZC - Centro de Desenvolvimento Sustentável das Zonas Costeiras (2011). Ministério de Coordenação da Ação Ambiental, Xai-Xai.

FRANCIS, M.. (1996). Community involvement and the management of vegetation in selected Communal areas in Zimbabwe Paper. Institute of Development studies (IDS), University of Zimbabwe.

GIL, A. C.. (2003). Métodos e Técnicas de Pesquisa Social. $5^{a}$ Ed.. São Paulo, Editora Futura.

HOGUANE, A. M. et al.. (2007). Manual de Gestão Integrada da Zona Costeira. Ministério de Coordenação da Ação Ambiental. Maputo. Universidade Eduardo Mondlane. Editora: UEM.

INE - Instituto Nacional de Estatística (2007). Illo Recenseamento Geral da População e Habitação. Moçambique. Maputo.

MAE - Ministério de Administração Estatal (1986). Atlas Geográfica. 2ª Ed. Editora INDE, Volume I, Moçambique.

MICOA - Ministério para Coordenação da Ação Ambiental (1998). MacroDiagnóstico da Zona Costeira de Moçambique. s/ed..Editora NORAD, Maputo.

(2005). As três convenções do rio e os respectivos protocolos. Direção Nacional de Gestão Ambiental. Maputo.

MOÇAMBIQUE, (2003). Decreto $n^{\circ}$ 43/2003, de 10 de Dezembro. Maputo.

MOÇAMBIQUE, (2006). Decreto $n^{\circ} 45 / 2006$ de 10 de Outubro. Maputo.

MUCHANGOS, Aniceto dos.. (1999). Moçambique Paisagens e Regiões Naturais. Maputo.

MULENGA, A. (2004). Introdução à Estatística. Universidade Eduardo Mondlane. Maputo.

POLETTE, M.. (2011). Perspectivas e diretrizes para governança da zona costeira. Universidade do Vale do Itajaí. Laboratório de Gestão Costeira Integrada. São Paulo. V SBO - Simpósio brasileiro de oceanografia: Oceanografia e políticas públicas. 55.47.3341-7717. Santos. Brasil. 